\title{
The Impact of Left to Right Eye Movement on Arab EFL/ESP Learners' Output*
}

\author{
Dr. Abdellah Benahnia \\ Casablanca: Morocco \\ English Language Center, King Fahad Medical City, Riyadh, Kingdom of Saudi Arabia
}

\begin{abstract}
Though a lot has been said about L2 acquisition and learners' output, there is still much to be done in terms of research pertaining to the cognitive part of eye movement based on the nature of the target language (TL) within the process of learning. Thus, eye movement according to the nature of L2 can be a challenge that learners might face. Arab EFL, or ESP learners might find it more difficult, taking into consideration the nature of the script of their Arabic language mother tongue (MT) going from right to left, and being a total opposite of all Anglo Saxon scripts (left to right). The following article tries to focus on the input process of Arab learners while trying to adapt to, or learn English as a foreign language, and find out if the paradox of eye movement which is left to right vs. right to left, (in the case of EFL/ESP learning), has any impact on these particular learners' actual output and performance.
\end{abstract}

Keywords: eye movement, reading span, learning, EFL Arab learners

\section{Introduction}

Though it has been claimed that lexical access cannot be the "engine" driving eye movements during reading, and that when and where the eyes move are instead primarily determined by visual and oculomotor factors (Reilly \& O'Regan, 1998), there are yet other claims that eye movement in reading scripts can be subject to habit formation. Burrhus Frederic Skinner (March 20, 1904-August 18, 1990), commonly known as B. F. Skinner, considered free will an illusion and human action dependent on consequences of previous actions. If the consequences are bad, there is a high chance that the action will not be repeated; if the consequences are good, the actions that led to it being repeated become more probable. Skinner called this process as "the principle of reinforcement". Skinner, also called the use of reinforcement to strengthen behavior operant conditioning, and he considered the rate of response to be the most effective measure of response strength. To study operant conditioning, he invented the operant conditioning chamber, also known as the Skinner Box, and to measure rate, he invented the cumulative recorder. Using these tools, he and C. B. Ferster produced his most influential experimental work, which appeared in the book Schedules of Reinforcement. His theory of "habit formation" can be advocated to justify the behavior of Arab learners when it comes to "Left-Right" eye movement practice while learning English. This unusual way (to these specific learners) of looking at a script (from left to right) may cause difficulty to many of them if not properly trained and tackled at an early stage

\footnotetext{
${ }^{*}$ Definitions: EFL: English as a Foreign Language; ESP: English for Specific Purposes; MCS: Memory, Cognitive and Spatial faculties.

Dr. Abdellah Benahnia, ELC Faculty Member \& Admin. Consultant, Ph.D. in Teaching Methods \& Curriculum Development, M.A. double major in Applied Linguistics \& TESOL, WVU, USA.
} 
and probably adopted as a reinforced habitual process and behavior. In general, we as humans tend to make approximately 250,000 eye movements each day. Some of those movements are unconscious or intentional, while others are controlled and purposefully geared towards a specific focal point or target, such as in the case of reading a text or a written passage.

Ancient Muslim linguists, and mainly the Arab ones, have pointed out that there is in fact a serious difficulty for an Arab learner to deal with Anglo-Saxon scripts and especially at the beginning stages of learning. It was also noticed even during the era of translating scientific and literary works and philosophy of the Greek thinkers and philosophers, that the fact of looking at those scripts and going from left to right was somehow confusing and slowing the pace of reading, or writing.

\section{A Linguistic Background Overview of Arabic Language}

Like the language of any other civilization, the Arabic language is often associated with the Arab world. However, due to the geopolitical situation associated with Muslim civilization and to the modern technology invasion, especially over this 21 st century, more and more people are curious about knowing about this language or even formally learning it. In fact, statistics show a great escalating demand for learning the Arabic language, the number of universities and institutions incorporating the teaching of Arabic in their programs, which has noticeably increased since the start of the Gulf war in the 90s. Moreover, due to the influence of Islam, the Arabic alphabet is one of the most widespread writing systems in the world, found in large parts of Africa, Western and Central Asia, as well as in ethnic communities in East Asia, Europe, and the Americas. While originally used to write the Arabic language, the Arabic alphabet has been adopted by other groups to write their own languages, such as Persian, Pashto, Urdu, and more (for more information on this subject, see the following link: (http://www.ancientscripts.com/arabic.html).

According to the same source, although Arabic inscriptions are the most common after the birth of Islam (7th century CE), the origin of the Arabic alphabet lies deeper in time. The Nabataeans, which established a kingdom in what is modern-day Jordan from the 2nd century BCE, were Arabs. They wrote with a highly cursive Aramaic-derived alphabet that would eventually evolve into the Arabic alphabet. The Nabataeans endured until the year $106 \mathrm{CE}$, when they were conquered by the Romans, but Nabataean inscriptions continue to appear until the 4th century CE, coinciding with the first inscriptions in the Arabic alphabet (which is also found in Jordan).

Unlike any other language, Arabic, generally speaking, has two variants to its alphabet: Kufic and Naskhi. The Kufic script is angular, which was most likely a product of inscribing on hard surfaces such as wood or stone, while the Naskhi script is much more cursive. The Kufic script appears to be the older of the scripts, as it was common in the early history of Islam, and used for the earliest copies of the Qur'an. We have to notice here that by the 11th century the Naskhi script appeared and started to gradually replace the Kufic script and started also to become the most popular script for copying not only the Qur'an, but other secular works as well as personal and literary writings among Arabs and those who adopted Arabic as their second, or foreign language. It is also important to note here that from the Naskhi script that the modern Arabic script style developed.

One more interesting feature that probably makes Arabic unique is not only in its phonological and vocalic sounds, but it has other features which are the multiple forms of a single letter. Depending on where in a word a letter appears, it could appear as an initial form (beginning of word), final form (end of word), or medial form (anywhere else). In addition, if the word has only one letter, then the isolated form is used. This in itself is a 
challenge not only to Arab learners, but to non-Arabic-speakers learners as well. However, learning English script is also a difficult task. As you know, the English alphabet is far from being a regular and consistent system of representing all the sounds in English. For instance, think of the letter groups such as "ough" as well as others and what sound would they produce or stand for.

We also have to note that even modern technology is incorporating Arabic language in its world of inventions due to the impact of business and the need of a vast audience of customers in trade. For example, Twitter is making the Internet a more non-English-friendly place. Twitter now comes in 28 languages - including Arabic, Farsi, Hebrew, and Urdu, which are written from right-to-left. In fact, it has long supported right-to-left text from users, but it now has instructions and can also display "hashtags" from right-to-left as well.

\section{Early Inherited Challenges for Arab EFL/ESP Learners}

It is very evident that it is not easy for a person whose mother tongue is Arabic, and who has been trained to read the cluster of letters staring from right to left, to quickly adapt to a new pattern of scripts that necessitates starting from left to right. This controversy may persist and stay with learners even at later stages of their studies. It is also very common, for example, to come across students (even at university level in the Gulf area) who might unintentionally be using their note books that they are using for English writing or note recording purposes (such as core lessons, or lecture notes), yet they are using them starting from right to left (even if their note books are actually with Arabic right-side margins!!!). When students are asked about that, the common response often heard is: "I am used to it". This in itself reinforces - to a great extent- the "habit formation" process advocated by Skinner. Moreover, young Arab learners usually start with the alphabet of their mother tongue language (Arabic). In North African countries such as Morocco, Algeria, and Tunisia, young students are not exposed to the second language alphabet (French) until they reach the 3rd grade. This is still debatable, because the majority of private schools are nowadays introducing both Arabic and French from day one in primary schooling and claiming that it is to the advantage of these young learners to face those challenges at an early stage. The Ministry of Education in those countries insists that mastery of the Arabic alphabet should take place first, and once it is realized during the first two years, young students or pupils can be exposed to other languages, bearing in mind, of course, the complexity of the Arabic script. Both opinions are supported by research, scientifically grounded advocacy and justification.

\section{Input Process Difficulties}

As Neufeld (1979) states so succinctly, the ultimate goal in second language learning research is to develop a model that explains how and why student performance varies in different learning tasks. Therefore, researchers emphasize the fact that reading and writing tasks remain the most critical areas in TL field. Not only because they both heavily depend on mastery of grammar and vocabulary, but they also depend on several other complex factors related to the phonological, morphological, syntactic and semantic form of the language, the cognitive parts on behalf of the learner, and most importantly the linguistic and paralinguistic factors and constituents of the learner's mother tongue language (such as the learner's socio-cultural background). According to Ajai P. Singh (2005 unpublished notes - passed on to me in Muscat, Oman, by the author himself), it is stated that, in natural settings, it is normally expected that the human head rocks from left to right while reading, or writing any text of an Anglo-Saxon language or script such as English. Consequently, the 
human mind draws sequential components or patterns of learning and understanding (assimilating meanings associated with the cluster of symbols on paper) to derive a meaning out of the text information that gets constituted by pattern-like neuronal firing in the memory, cognitive and spatial faculties (MCS) or modules. Hence, the human brain which subsequently gets trained and systematically coordinates (in a highly sophisticated way) with other higher faculties in order to link, or attribute specialized references to those symbols or cluster of words. During this rocking movement of the head along with the eyeballs, when the mental focus (attention) goes on to the next line to read again from left to right, the brain optical area gets signals that do not get entangled with MCS sector or module as the reading is not attempted because the text runs into illegible mode. All this process of optical recognition, i.e., head/eye movement, MCS participation is a natural and uninterrupted process for an English reader, having an innate acumen of long historical practice since a very early age (ibid.). This process does not seem to be a difficult task since the person has gone through a stage of natural habit formation that becomes a habitual mechanical process. Some researchers go on to a further level of discussion in this regard, to even advocate that this process itself may be genetic as well (this of course would need further, deeper research that looks at a large segment of population, cross-checking via a control group and in various locations or communities to prove its validity).

To come back to the reading practice, we can say that making sense of what you read is no doubt a cognitive practice that varies from one person to another in terms of time and fixation span and comprehension. In other words, there are people who cannot generate meaning from a text by separating its constituents and using the process of fragmentation, i.e., looking at all small details to build up that full picture (those people may be referred to as "field independent"), but they will rather generate meaning or reference only (and probably only if) they look at the whole picture or text (these people may be referred to as "field dependent"). Moreover, psychological research literature on field independence indicates that a field-independent person possesses enhanced cognitive restructuring abilities, while a field-dependent individual is likely to possess well-developed interpersonal skills. Furthermore, it was hypothesized that field independence would be related to the acquisition of linguistic competence, and that field dependence would be related to the acquisition of communicative competence. In other words, field independence will be looking at the linguistic details pertaining to the pattern or cluster of words that would help the learners to attribute a semantic meaning to those patterns, hence helping them in attaining linguistic knowledge or acquisition. However, the dependent field would rather be the motor assisting the learner to produce meaningful output as a form of acquired performance. As Ajai P. Singh clarified, taking an example of an abstract painting, the onlooker, after an initial glimpse, settles for the first recognition component to get a clue to understand the complete art (picture). Then he looks for other components, or sectors in the art to make a complete mental picture or pattern for deriving a logical sense of information and thereafter for an emotional response through appreciation of any degree. What makes a clear mental picture of what we see or read then, can be derived by following two distinct cognitive streams of processes relying on either a holistic approach, or a fragmented approach. Therefore, if the picture or sequence of patterns is a little complicated, overlapped, or cress-crossed, the initial clues - and later more connecting clues - are probed to form the complete mental picture for drawing some sense out of it. So, the main objective of simple observation is recognition to make the object in question recognizable to get some meaning/understanding for the purpose of knowledge, or acquisition. However, other than in common reading process, for the majority of the population, and in general, people tend to use different directions with their eyes (as illustrated by the map below). It indicates what kind of imaginative process is going on in someone's brain 
when their eyes point in a particular direction. Researchers have come out with ways of how to interpret eye movement as a body language. As some interesting examples, as stated by Jordan Lejuwaan (unspecified date on website), for example, if you see someone looking down-right, you could recognize the internal dialogue and ask them what they are thinking about. Or if you see someone looking up to the right or left, you could ask what they are trying to remember. Also, and most interestingly, the author suggests a surprising way to detect lies, i.e., if you ask your (person in your life) where he/she was last night and they look to the left, you know that they are constructing an answer, not remembering one! Hence they are lying. The following Figure 1 shows the different possible eye movements a person can do depending on the context or situation:

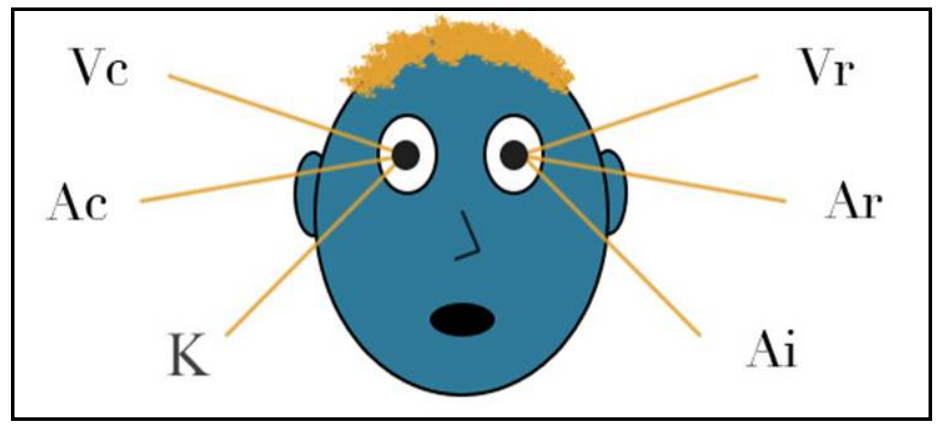

Figure 1. What kind of imaginative process is going on in someone's brain when their eyes point in a particular direction (created by Jordan Lejuwaan, adapted and adjusted by author). ${ }^{1}$

However, an Arab student whose optical adjustment with head/eye movement, MCS is by birth tuned in reverse order, right to left, (as seen by Anglo-Saxon language speakers), i.e., recognizing linguistic patterns especially, or any form of art or any kind English material, he would probably look at it at first glance from right to left. As such when an Arab student reads English passages-the unconscious jolt creates some subconscious barriers that restrict the smooth propagation of neuronal impulses that could normally occur due to head/eye, MCS coordinated passage pattern. This interrupted process influences the reading recognition understanding capabilities of Arabs in terms of speed, fluency of language and complete orientation of mental processing for assimilation of the holistic meaning attributed to the text. It then starts reflecting in the performance and learning outputs of the subject and the theme of the reading material is never totally assimilated. Moreover, when grammar and hard words are becoming more lofty obstacles, it does develop apathy and personal restrictions for giving more room for practice and perfecting in learning English language. Furthermore, Arab learners (especially in the Gulf area) tend to face difficulties in differentiating between some English letter sounds such as: "p" and "b" and "f" and "v". Since "p" and "v" do not exist in the Arabic alphabet, many students tend to pause when they see them in a word and release them as " $b$ " and " $f$ " (causing confusion and misunderstanding to the listener). This leads them to a larger perceptual time span and fixation of sight, and to the monitoring status impeding the normal flow of communication and utterances as expected.

\section{How to Overcome Eye Left to Right Movement Difficulties}

To overcome the above mentioned problem of learning English for Arab learners, and mainly left to right eye movement, special physical, psychological and mental focusing exercises and procedures are recommended

${ }^{1}$ Vc: Visual Construct; Vr: Visual Recall; Ac: Auditory Construct; Ar: Auditory Recall; K: Kinesthetic; Ai: Auditory Internal Dialogue.

Note: This is for right handed people only. For left-handers, simply switch left and right! 
to reorient the reading/writing abilities among Arab EFL learners. Novice teachers must be oriented and trained in that respect. This may be time consuming exercise, but would surely transform the predisposed mental involuntary habit of reading and recognizing patterns that are written from left to right, and would help to recognize and understand the new pattern of English. Not only that, but this could be experimented by putting the learners through several reading and writing activities and drills. Reading activities in small groups or pairs would enhance not only the vocalic sounds or accent via speaking, but also train the learners to read much faster (going left to right). Consecutive and continuous practice is the key to success in this respect that leads to molding students into a habit formation of looking at English scripts from left to right without difficulty. Putting training groups on trials and testing them for their recognizing, understanding and reading speed skills with the percentage of correctness, is another way of helping learners to overcome those difficulties. Excessive writing drills are a key factor to overcoming those problems as well.

Furthermore, reading eye movements are saccadic eye movements, i.e., when reading, we make a series of fixation-saccade-fixation sequences. Generally, each word is fixated, slightly to the left of the center of the word. Larger words will have multiple fixations within them. The average duration of each fixation is about $250 \mathrm{msec}$ in the case of a mature reader. As expected, it is much larger in beginning readers ( $>500 \mathrm{msec}$ ). Therefore, reading practice should be gradual from smaller to larger passages. However, beginning learners must start with the alphabet and word formation before they move on to sentence level. Hence, novice learners should not be exposed to larger reading passages before mastering the basic skills of putting the letters together (from left to right), generating their meaning, and being able to put them in the right syntactic order in the process of writing, with the assumption that there is a tight link between eye-movement control and language processing during reading, i.e., language processing determines when and/or where the eyes move.

\section{Conclusion and Recommendations}

It is evidently clear that eye movements reflect moment-by-moment cognitive processing demands during reading (e.g., Just \& Carpenter, 1987). Target language learners, such as Arab learners trying to adapt to the English language script, for example, may find it very challenging especially at early stages of their learning journey (that is, adjust their eye movement to accommodate the text difficulty level and starting from left to right direction). Though there are two theoretical "camps" that represent the extremes, or end-points, of a theoretical continuum regarding eye movement in dealing with left to right direction, the best available evidence suggests a more intermediate position, in which language processing primarily controls when the eyes move, while visual processing and properties of the oculomotor system control where the eyes move (Reichle, Pollatsek, Fisher, \& Rayner, 1998). Therefore, adjusting to a new type of language that necessities a contrary eye movement (such as left to right for Arab learners while learning English) is subject to several difficulties or obstacles such as:

- The eyes (and mind) do not seem to move smoothly across the page (unlike while they are reading Arabic scripts), where they should be only stopping (or reversing) when they pause to think or when they encounter some difficulty understanding what they are reading.

- Possibility of having a high rate of fixation (especially when the spacing gets higher).

- Left and right boundaries of the perceptual span may be constituted differently, i.e., for Arab learners trying to adjust their reading process to the English script, may realize that the left boundary is defined by the beginning (i.e., left edge) of the word that is being fixated, while the right boundary is defined by the number of 
visible letters (for further insight regarding this fact, see for example Radach \& McConkie (1998)). The allocation of attention and the perceptual span might be quite obvious if you watch Arab learners trying to read English texts.

- Inconsistency regarding the spelling of words in English and the phenomenon of "silent" letters.

- The English alphabet is far from being a regular and consistent system of representing all the sounds in English.

- Inexistence of the letter sound "p" and " $v$ " in Arabic.

Finally, it is highly recommended that Arab learners of EFL/ESP English courses must spend a quite large amount of time in practicing reading and writing via individual and group activities. Eye movement direction can be adjusted allowing learners to save time of perceptual span, and gain speed, energy, and the mind to visualize comprehensive pictures and accurate perception. Teachers must also bear in mind that most normal humans acquire a basic competence in their first language, second language learners display great variability in the level of proficiency they attain in the new tongue. Hence, Arab learners must gradually be exposed to different types of word sequences, different syntactic options, and different clusters of words at sentence level, paragraph level, and lengthy passages, but using a step-by-step process of exposure to ensure improvement of left to right visual reading speed, comprehension, and mastery of new vocabulary and spelling.

\section{References}

Asher, J. J., \& García, R. (1969). The optimal age to learn a second language. The Modern Language Journal.

Bakhtin, D. (2005). At the seaside: Utopia modernity and the carnivalesque in theory. Culture and Society, 22(3).

Benahnia, A. (1992). The cultural component in EFL textbooks used in Morocco (M.A. thesis). Morgantown: WVU.

Benahnia, A. (2010). The role of cultural components in shaping the L2 learner's identity and intercultural competence. Paper presented at 2012 Kingdom of Saudi Arabia Association of Language Teachers Conference.

Bialystok, E. (1997). The structure of age: In search of barriers to second language acquisition. Second Language Research.

Bouma, H., \& de Voogd, A. H. (1974). On the control of eye saccades in reading. Vision Research.

Brooks, N. (1976). The analysis of foreign and familiar cultures. In R. C. Lafayette, The culture revolution in foreign language teaching. Illinois: National Textbook Company.

Chamberlain, S. P. (2005). Recognizing and responding to cultural differences in the education of culturally and linguistically diverse learners. Intervention in School and Clinic, 40, 195-211.

Elizabeth, G. (2015). Freud's theory of developmental phases. Retrieved from http://www.kidsdevelopment.co.uk/freudsdevelopmentaltheory.html

Elliott, R. E. (1995). Field independence/dependence, hemispheric specialization, and attitude in relation to pronunciation accuracy in Spanish as a foreign language. The Modern Language Journal.

Erik, D. (1999). Comparing the E-Z reader model to other models of eye movement control in reading. Amherst: Reichle University of Pittsburgh Keith Rayner and Alexander Pollatsek University of Massachusetts.

Fathman, A. (1975). The relationship between age and second language productive ability. Language Learning.

Finnermann, M. D. (1987). Liberating the foreign language syllabus. The Modern Language Journal, 7(1).

Flege, J. E. (1987). A critical period for learning to pronounce foreign languages? Applied Linguistics.

Flege, J. E. (1988). Factors affecting degree of perceived foreign accent in English sentences. Journal of the Acoustical Society of America.

Flege, J. E. (1998). Age of learning and second-language speech. In D. Birdsong (Ed), New perspectives on the critical period hypothesis for second language acquisition. Mahwah, New Jersey.

Flege, J. E., MacKay, I. R. A., \& Piske, T. (2001). Factors affecting degree of foreign accent in an L2: A review. Journal of Phonetics.

Frazier, L., \& Rayner, K. (1982). Making and correcting errors during sentence comprehension: Eye movements in the analysis of structurally ambiguous sentences. Cognitive Psychology.

Hall, Jr., \& Robert, A. (1973). New ways to learn a foreign language. New York: Spoken Languages Services, Inc.. 
Hansen, J., \& Stanfeld, C. (2012). Field dependence-independence as a variable in second language cloze test performance. TESOL Quarterly, 101-131.

Henderson, J. M., \& Ferreira, F. (1990). Effects of foveal processing difficulty on the perceptual span in reading: Implications for attention and eye movement control. Journal of Experimental Psychology: Learning, Memory, and Cognition.

Henderson, J. M., \& Ferreira, F. (1993). Eye movement control during reading: Fixation measures reflect foveal but not parafove al processing difficulty. Canadian Journal of Experimental Psychology.

Huang, Y., \& Zhu, Y. D. (2009). The role of local communities and the shift of L2 learners' frame of reference in second language acquisition. SFU Educational Review, 1, 22-29.

John, S., \& Tang, R. (1999). The "I" in identity: Exploring writer identity in student academic writing through the first person pronoun. English for Specific Purposes, 18(Supplement 1).

Just, M. A., \& Carpenter, P. A. (1987). The psychology of reading and language comprehension. ERIC Journal.

Just, M. A., \& Carpenter, P. A. (1992). A capacity theory of comprehension: Individual differences in working memory. Psychological Review, 99(1), 122-149.

Kennedy, R., Radach, D. H., \& Pynte, J. (Eds). Reading as a perceptual process (pp 269-300). Amsterdam: North Holland.

Kramsh, C. J. (1988). The cultural discourse of foreign language textbooks. In Toward a new integration of language and culture. U.S.A.: Northeast Conference on the Teaching of Foreign Languages.

Lafayette, R. C. (1988). Integrating the teaching of culture into the foreign language classroom. In Toward a new integration of language and culture. U.S.A.: Northeast Conference on the Teaching of Foreign Languages.

Lantolf, J. P., \& Pavlenko, A. (1995). Socio-cultural theory and second language acquisition. Annual Review of Applied Linguistics.

Lejuwaan, J. (n.d.). How to read eye movements. Retrieved from http://highexistence.com/reading-eye-movements/

Lin, L. F. (2009). Second language learners' identity toward their home culture: Adding pragmatic knowledge to language learning curriculum. Asian Social Science Journal, 5(8).

McConkie, G. W., Kerr, P. W., \& Dyre, B. P. (1994). What are "normal" eye movements during reading: Toward a mathematical description. In J. Ygge and G. Lennerstrand (Eds.), Eye movements in reading (pp. 315-328). Oxford, England: Pergamon Press.

Mercedes, M., \& Vaughn, B. (2007). Strategic diversity \& inclusion management magazine (pp. 31-36). San Francisco, CA: DTUI Publications Division.

O'Regan, J. K. (1990). Eye movements and reading. In E. Kowler (Ed.), Eye movements and their role in visual and cognitive processes (pp. 395-453). Amsterdam: Elsevier.

Pierce, N. (1995). Social identity, investment, and language learning. TESOL Quarterly, 29(1), 9-31.

Pollatsek, A., \& Rayner, K. (1982). Eye movement control in reading: The role of word boundaries. Journal of Experimental Psychology: Human Perception and Performance.

Pollatsek, A., Rayner, K., \& Balota, D. A. (1986). Inferences about eye movement control from the perceptual span in reading. Perception \& Psychophysics.

Pollatsek, A., Rayner, K., Fischer, M. H., \& Reichle, E. D. (1999). Attention and eye movements in reading. In J. Everatt (Ed.), Reading and dyslexia: Visual and attentional processes (pp. 179-209). London: Routledge.

Radach, R., \& McConkie, G. W. (1998). Determinants of fixation positions in words during reading. In G. Underwood (Ed.), Eye guidance in reading and scene perception (pp. 77-100). Oxford: Elsevier.

Rayner, K. (1978). Eye movements in reading and information processing. Psychological Bulletin, 85, 618-660.

Rayner, K., \& Frazie, R. L. (1989). Selection mechanisms in reading lexically ambiguous word. Journal of Experimental Psychology: Learning, Memory, and Cognition.

Rayner, K., \& McConkie, G. W. (1976). What guides a reader's eye movements. Vision Research.

Rayner, K., \& Sereno, S. C. (1994). Eye movements in reading: Psycholinguistic studies. In M. Gernsbacher (Ed.), Handbook of psycholinguistics (pp. 57-82). New York: Academic Press.

Rayner, K., Reichle, E. D., \& Pollatsek, A. (1998). Eye movement control in reading: An overview and model. In G. Underwood (Ed.), Eye guidance in reading and scene perception (pp. 243-268). Oxford: Elsevier.

Rayner, K., Sereno, S. C., Morris, R. K., Schmauder, A. R., \& Clifton, C. (1989). Eye movements and on-line language comprehension processes. Language and Cognitive Processes, 4(Special issue), 21-49.

Reichle, E. D., Pollatsek, A., Fisher, D. L., \& Rayner, K. (1998). Toward a model of eye movement control in reading. Psychological Review. 
Reichle, E. D., Rayner, K., \& Pollatsek, A. (1999). Eye movement control in reading: Accounting for initial fixation locations and refixations within the E-Z Reader model. Vision Research, 39, 4403-4411.

Reilly, R., \& O'Regan, J. K. (1998). Eye movement control in reading: A simulation of some word-targeting strategies. Vision Research, 38, 303-317.

Sagi, D., \& Julesz, B. (1985). "Where" and "what" in vision. Science.

Schroyens, W., Vitu, F., Brysbaert, M., \& d'Ydewalle, G. (1999). Eye movement control during reading: Foveal load and parafoveal processing. Quarterly Journal of Experimental Psychology.

Seelye, H. N. (1984). Teaching culture. U.S.A.: National Textbook Company.

Seidenberg, M. S. (1989). Visual word recognition and pronunciation: A computational model and its implications. In W. Marslen-Wilson (Ed.), Lexical representation and process (pp. 25-74). Cambridge, M A: MIT Press.

Sereno, S. C. (1992). Early lexical effects when fixating a word in reading. In K. Rayner (Ed.), Eye movements and visual cognition: Scene perception and reading (pp. 304-316). New York: Springer-Verlag.

Sereno, S. C., Rayner, K., \& Posner, M. I. (1998). Establishing a time-line of processing during reading: Evidence from eye movements and even t-related potentials. NeuroReport.

Sparks, D. L., \& Mays, L. (1990). Signal transformations required for the generation of saccadic eye movements. Annual Review of Neuroscience.

Thanasoulas, D. (2001). The importance of teaching culture in the foreign language classroom. Radical Pedagogy, 3(3).

Tylor, E. B. (1871). Primitive culture: Researches into the development of mythology, philosophy, religion, language, art and custom. New York: Henry Holt.

Wenger, E. (1991). Toward a theory of cultural transparency: Elements of a social discourse of the visible and the invisible (Ph.D. dissertation, Institute for Research on Learning, Palo Alto, CA).

Wiley, J., \& Rayner, K. (2000). Effects of titles on the processing of text and lexically ambiguous words: Evidence from eye movements. Memory \& Cognition, 28, 1011-1021

Zola, D. (1984). Redundancy and word perception during reading. Perception \& Psychophysics. 